\title{
ELECTRON INJECTOR STUDIES AT LBL *
}

\author{
Charles H. Kim \\ Lawrence Berkeley Laboratory, University of California \\ 1 Cyclotron Road, Berkeley, California 94720
}

\begin{abstract}
s
Two recent LBL design studies,(1) an rf gun with a laser driven photocathode, (2) and a conventional thermionic gun with three stages of bunching, are summarized and compared. The rf gun was designed as a possible injector to a $1 \mathrm{GeV}$ test experiment consisting of a high gradient $\mathrm{rf}$ structure and a relativistic klystron. The rf gun cavity had $(1 / 2+2)$ cells. Analytic calculations and computer simulations suggest that emittance growth was mainly caused by space-charge effects and the rf fringe field effects at the exit of the last cell. Emittance growth was found to be strongly dependent on the size and the length of the pulse. The conventional gun is being considered as an injector for the proposed Infra-Red-Free-Electron-Laser (IRFEL) facility. In order to reduce the space charge effects the final bunching is done in a tapered Lband tank where acceleration and bunching occur at the same time. Beam emittance of a conventional gun was measured at the ALS gun-test-stand and found to be satisfactory for the IRFEL application.
\end{abstract}

\footnotetext{
* This work was supported by the Director, Office of Energy Research, Office of Basic Energy Sciences, Material Sciences Division, U.S. Department of Energy, under contract number DE-AC03-76SF00098
} 


\section{Introduction}

There has been great interested in bright electron sources because they are required (1) for future high energy physics applications, (2) for free-electron-laser (FEL) applications, and (3) for studying beam dynamics of intense bright electron beams. X-ray holography using an $\mathrm{x}$-ray FEL requires an extremely low emittance high intensity electron beam which is beyond the presently available technology. We have recently made two injector design studies which are summarized and compared in this paper.

An $\mathrm{rf}$ gun with a laser-driven photocathode was investigated as a possible injector to a 1 GeV high gradient rf linac(1). This work was a part of the LLNL-SLAC-LBL collaboration on demonstrating the feasibility of a compact rf linac $(1 \mathrm{GeV},<5 \mathrm{~m})$. The "1 GeV test experiment" would consist of a bright electron injector, an efficient high-power microwave source such as the relativistic klystron, and a high-gradient accelerating structure. Interesting beam dynamics calculations and some scaling laws came out of this study which are described in section 2 .

Section 3 describes a design of a highly stable rf linac with a conventional injector consisting of a thermionic electron gun and three low-frequency bunchers(2),(3). The $50 \mathrm{MeV}$ linac was designed for the Infra-Red-Free-Electron-Laser (IRFEL) facility of the proposed Chemical Dynamics Research Laboratory (CDRL) at LBL. The CDRL is an integrated user facility for research in chemical dynamics and is a part of a broader initiative called the Combustion Dynamics Facility (CDF) which is being proposed jointly with Sandia National Laboratory to address outstanding problems in combustion science. The IRFEL can be synchronized with the Advanced Light Source ( a synchrotron radiation facility under construction at LBL) and with other advanced lasers, providing a powerful tool to study chemical reaction dynamics. The conventional technology was chosen for the injector because of its reliability and stability. Careful beam line design and stability analysis were necessary to achieve the required brightness and to assure the stability.

\section{Injector for the $1 \mathrm{GeV}$ Test Experiment}

The desirable injector parameters for the " $1 \mathrm{GeV}$ Test Experiment" are summarized in Table I. They were specific to the particular use of the LLNL induction linac and the design of the high gradient structure.

The structure of the rf gun cavity is schematically shown in figure 1 . The cavity consisted of $(1 / 2+2)$ cells which are driven in the $\pi$ mode: The first cell has a half wavelength cell so that electrons see the maximum electric field as they are emitted from the cathode. The two full cells accelerate electrons to a high enough energy so that the undesirable space charge effects and the nonlinear exit optics are reduced. 
Table I.

\begin{tabular}{lc}
\hline Linac fundamental frequency & $11.4 \mathrm{GHz}$ \\
Charge per micropulse & $1-4 \mathrm{nC}$ \\
Micropulse duration & $2-6 \mathrm{pS}$ \\
Peak Current & $300-600 \mathrm{Amps}$ \\
Macropulse duration & $20 \mathrm{nS}$ \\
Number of Micropulses in one macropulse & $5-10 \mathrm{pulses}$ \\
Emittance $\left(\gamma \sigma_{\mathrm{x}} \sigma_{\mathrm{x}^{\prime}}\right)$ & $8-30 \mathrm{~mm}$-mrad \\
\hline
\end{tabular}

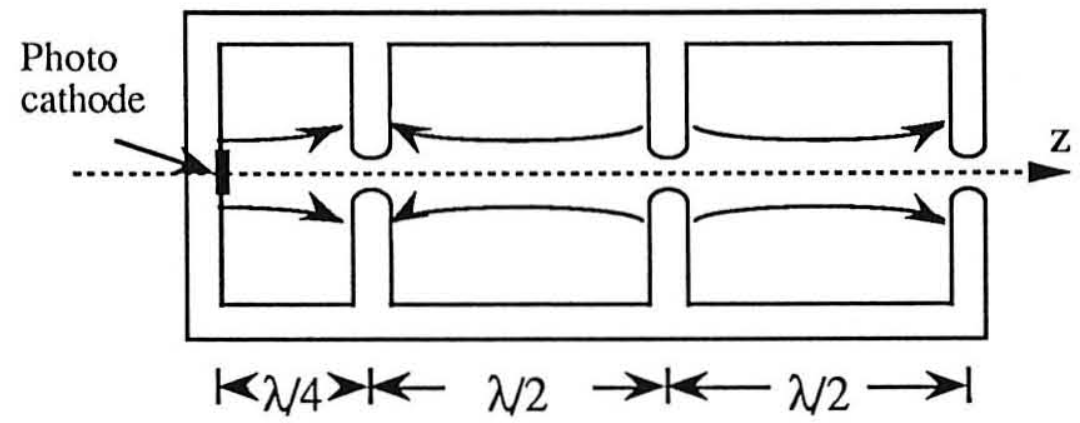

Figure 1. Schematic diagram of the rf gun

Beam dynamics in the rf gun was studied analytically (4) and by simulation. ${ }^{(5)}$ The analytic model provides a simple formulae for the rf and space charge contributions to the transverse and longitudinal emittances:

$$
\begin{gathered}
\varepsilon_{\mathrm{x}}^{\mathrm{rf}}=(\alpha \mathrm{k} / \sqrt{2}) \sigma_{\mathrm{x}}^{2}\left(\mathrm{k} \sigma_{\mathrm{z}}\right)^{2} \\
\varepsilon_{\mathrm{z}}^{\mathrm{rf}}=\sqrt{3}\left(<\gamma_{\mathrm{f}}>-1\right) \mathrm{k}^{2} \sigma_{\mathrm{z}}^{3} \\
\varepsilon_{\mathrm{i}}^{\mathrm{Sc}}=\left[1 / \sin \left(\phi_{\mathrm{o}}\right)\right][\mathrm{I} / \mathrm{I} \mathrm{A}] \mu_{\mathrm{i}}(\mathrm{A}), \quad(\mathrm{i}=\mathrm{x} \text { or } \mathrm{z})
\end{gathered}
$$

where $\lambda$ is the $\mathrm{rf}$ wave length, $\mathrm{k}=2 \pi / \lambda, \mathrm{E}_{\mathrm{O}}$ is the maximum gradient, $\alpha \mathrm{k}=\mathrm{eE}_{\mathrm{O}} /\left(2 \mathrm{mc}^{2}\right)$ is the normalized maximum electric field gradient, $\sigma_{\mathrm{X}}$ and $\sigma_{\mathrm{X}}$ are transverse size and length of the electron beam, $A=\sigma_{X} / \sigma_{Z}$ is the aspect ratio of the bunch, $I_{A}$ the Alfven current, I the peak 
current, and $\phi_{\mathrm{o}}$ initial rf phase of the beam center. The space-charge form factor, $\mu_{\mathrm{i}}(\mathrm{A})$ are given as:

$$
\begin{gathered}
\mu_{\mathrm{x}}(\mathrm{A})=\sqrt{\left.<\mathrm{E}_{\mathrm{x}}^{2}><\mathrm{x}^{2}>-<\mathrm{E}_{\mathrm{x}} \mathrm{x}\right\rangle^{2}} \\
\mu_{\mathrm{z}}(\mathrm{A})=\sqrt{\left.<\mathrm{E}_{\mathrm{z}}{ }^{2}><\Delta \mathrm{z}^{2}>-<\mathrm{E}_{\mathrm{z}} \Delta \mathrm{z}\right\rangle^{2}}
\end{gathered}
$$

where $E_{i}=\left(4 \pi \varepsilon_{o} / n_{0}\right) E_{i} s c(i=x, z)$ is the normalized electrostatic field and $n_{o}$ is the line charge density. The $\mu_{\mathrm{i}}(\mathrm{A})$ factors depend only on the aspect ratio of the bunch. The results agree reasonably well with the PARMELA simulations. The total emittance of the beam is expected to be

$$
\sqrt{\left[\left(\varepsilon_{i}^{r f}\right)^{2}+\left(\varepsilon_{i}^{s c}\right)^{2}\right]}<\varepsilon_{i}<\varepsilon_{i}^{r f}+\varepsilon_{i}^{s c}
$$

PARMELA, modified by McDonald to include the emission of electrons from a photocathode by a laser pulse ${ }^{(6)}$, has been used to simulate beam dynamics in the rf cavity. Six different cases were simulated for the cavity geometry shown in figure 1 for different frequencies, field gradients, and the laser pulse durations (5). The results are summarized in Table II.

Table II. PARMELA runs for the rf gun. Charge per micropulse was $1 \mathrm{nC}$ and the laser spot size was $3 \mathrm{~mm}$ rms for all the cases. No external focusing was assumed.

\begin{tabular}{lrrrrrr}
\hline Frequency $(\mathrm{MHz})$ & 1269 & 1269 & 1269 & 1269 & 2856 & 2856 \\
Max Field on cathode $(\mathrm{MV} / \mathrm{m})$ & 30 & 30 & 60 & 60 & 60 & 60 \\
Injection Phase, $\phi_{\mathrm{O}}\left(^{\circ}\right)$ & 58 & 58 & 70 & 70 & 47 & 47 \\
laser pulse half width $(\mathrm{ps})$ & 2 & 6 & 2 & 6 & 2 & 6 \\
peak current $(\mathrm{Amps})$ & 133 & 82 & 212 & 118 & 212 & 106 \\
Initial Emittance $\left(\gamma \sigma_{\mathrm{X}} \sigma_{\mathrm{X}^{\prime}}\right.$ mm-mrad) & 0.56 & 0.56 & 0.56 & 0.56 & 0.56 & 0.56 \\
'Final Emittance $\left(\gamma \sigma_{\mathrm{X}} \sigma_{\mathrm{X}^{\prime}}\right.$ mm-mrad) & 17 & 13 & 13 & 8 & 14 & 10 \\
Beam energy $(\mathrm{MeV})$ & 5 & 5 & 10 & 10 & 4 & 4 \\
energy jitter $\left(10^{-4}\right)$ & 4 & 2 & 2 & 2 & 4 & 8 \\
energy spread $\Delta \gamma / \gamma(\%)$ & 0.7 & 0.6 & 0.3 & 0.2 & 0.5 & 0.3 \\
final x' (mrad) & 9 & 8 & 6 & 5 & 13 & 12 \\
exit $\mathrm{x}_{\mathrm{rms}}(\mathrm{mm})$ & 4.1 & 3.7 & 3.0 & 2.8 & 3.2 & 3.0 \\
exit dz $\mathrm{rms}_{\mathrm{rmm}}(\mathrm{mm})$ & 0.8 & 1.3 & 0.5 & 0.9 & 0.5 & 1.0 \\
\hline
\end{tabular}


In light of the simple model, the transverse emittance growth were mainly caused by the space charge effects and the longitudinal emittance growth by the rf fields.

A Nd-YaG laser $(532 \mathrm{~nm})$ was considered on a $\mathrm{Cs}_{3} \mathrm{Sb}$ photocathode surface with a quantum yield of $10^{-2}$. A $0.5 \mu \mathrm{J} /$ pulse laser would produce $2 \mathrm{nC} /$ pulse of electrons. The laser micro-pulses are 15 ps FWHM $423 \mathrm{MHz}$ with a timing jitter of 1 ps absolute. The life time of the cathode is expected to be about 20 hours.

\section{Electron Injector for the IRFEL / CDRL}

The IRFEL requirements and parameters were determined carefully after a number of workshops in which many prospective users of CDRL and accelerator designers have participated. Table III summarizes the IRFEL parameters, which are characterized by the unusually stringent stability requirements. The micropulse repetition rate of $36.56 \mathrm{MHz}$ was chosen such that every third IRFEL pulse coincide with one of the ALS pulses if the storage ring has 8 equally spaced electron bunches. This frequency is also close to those of commercially available advanced lasers.

Table III. IRFEL Design Requirements

\begin{tabular}{lr}
\hline Wave Length (continuously tunable) & $3-50 \mu$ \\
Micropulse energy (for $3 \mathrm{~m}$ ) & $100 \mu \mathrm{J}$ \\
Micropulse duration & $10-50 \mathrm{ps}$ \\
Micropulse repetition rate $\left(3 \times \mathrm{f}_{\mathrm{ALS}}\right)$ & $36.56 \mathrm{MHz}$ \\
Macropulse duration & $100 \mu \mathrm{s}$ \\
Macropulse repetition rate & $60 \mathrm{~Hz}$ \\
Average Power & $20 \mathrm{~W}$ \\
Wave length jitter, $\delta \lambda / \lambda$ (without gratings) & $<10-3$ \\
Wave length jitter, $\delta \lambda / \lambda$ (with gratings) & $<10-4$ \\
Intensity Jitter, $\delta \mathrm{I} / \mathrm{I}$ & $<10^{-1}$ \\
\hline
\end{tabular}

The accelerator system was designed specifically to meet these IRFEL requirements. A schematic diagram of the accelerator system is shown in figure 2 . It consists of a conventional thermionic electron gun, a $146 \mathrm{MHz}$ buncher, a $512 \mathrm{MHz}$ buncher, an L-band buncher and two L-band $25 \mathrm{MeV}$ linac tanks. The linac parameters and beam parameters at linac exit are summarized in Table IV. In order to meet the stability requirements of FEL, various sources of jitter were identified and schemes to stabilize them were studied.

The electron gun has a conventional thermionic cathode with quite moderate requirements as shown in Table V. The time structure of FEL pulses mimics that of the electron pulses. The 


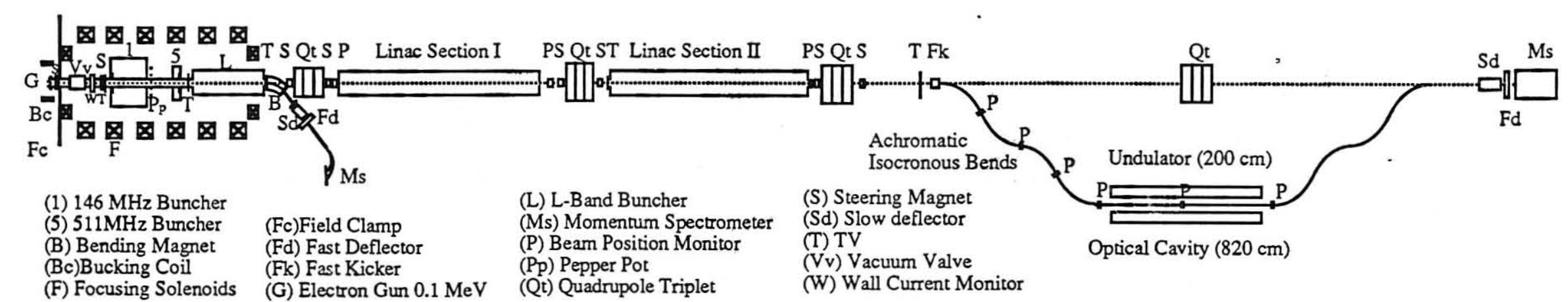

Figure 2. Schematic diagram of the accelerator system

Table IV. The linac and beam parameters

\begin{tabular}{lc}
\hline Energy & $23-51 \mathrm{MeV}$ \\
Micropulse peak current & $100 \mathrm{~A}$ \\
Number of electrons / micropulse & $1-2 \mathrm{nC}$ \\
Pulse Duration $(\mathrm{FWHM})$ & $5-20 \mathrm{psec}$ \\
Gun frequency, $\mathrm{F}_{\text {gun }}\left(3 \mathrm{x} \mathrm{f}_{\mathrm{ALS}}\right)$ & $36.56 \mathrm{MHz}$ \\
Linac rf frequency $\left(35 \mathrm{f} \mathrm{f}_{\text {gun }}\right)$ & $1279.6 \mathrm{MHz}$ \\
Emittance $\left(\gamma \sigma_{\mathrm{X}} \sigma_{\mathrm{x}^{\prime}}\right)$ & $2.0 \times 10^{-5} \mathrm{~m}-\mathrm{rad}$ \\
Energy spread, $\delta \mathrm{E} / \mathrm{E}(50 \mathrm{MeV})$ & $5 \times 10^{-3} \mathrm{FWHM}$ \\
Macropulse repetition rate & $<60 \mathrm{~Hz}$ \\
Energy jitter, $\delta \mathrm{E} / \mathrm{E}(<0.3 \mathrm{MHz})$ & $5 \times 10^{-4}$ \\
Time jitter, $\delta \tau(<0.3 \mathrm{MHz})$ & $0.1 \mathrm{ps}$ \\
Transverse position jitter & $<0.1 \sigma_{\mathrm{X}}$ \\
Transverse angular jitter & $<0.1 \sigma_{\mathrm{x}^{\prime}}$ \\
\hline
\end{tabular}

Table V. Gun parameters

\begin{tabular}{lc}
\hline extraction voltage & $100 \mathrm{kV}$ \\
current & $1-2.5 \mathrm{Amp}$ \\
micropulse duration & $1-2 \mathrm{nsec}$. \\
micropulse repetition rate & $36.56 \mathrm{MHz}$ \\
macropulse duration & $100 \mu \mathrm{sec}$. \\
emittance $\left(\gamma \sigma_{\mathrm{X}} \sigma_{\mathrm{x}^{\prime}}\right)$ & $2.5 \times 10^{-6} \mathrm{~m}-\mathrm{rad}$ \\
Charge jitter, $\delta \mathrm{Q} / \mathrm{Q}$ & 0.02 \\
Current jitter, $\delta \mathrm{I} / \mathrm{I}$ & 0.02 \\
Extraction $\mathrm{Voltage}$ jitter, $\delta \mathrm{V} / \mathrm{V}$ & 0.002 \\
Grid voltage jitter, $\delta \mathrm{V} / \mathrm{V}$ & 0.01 \\
Gun timing jitter & $<10 \mathrm{ps}$ \\
\end{tabular}


146 and $512 \mathrm{MHz}$ bunchers have the standard reentrant-cavity geometries. The frequencies of the bunchers and the linac are integral multiples of the gun frequency $(4,14$, and 35 times the gun frequency, respectively). Rf voltages of $<80 \mathrm{kV}$ zero-to-peak are required for the bunchers.

Longitudinal space charge effects are very strong at the end of the second buncher, which suggests that further bunching must be done at a higher beam energy. The purpose of the Lband buncher is to combine acceleration and bunching such that emittance growth caused by space-charge effects are reduced. The L-band buncher is a standing-wave tank consisting of nine side-coupled-cavities ${ }^{(8)}$ whose lengths varies to accommodate the increasing velocity of electrons as shown in figure 3. The 4-th cell is longer than others so that the additional phase shift in that cell places the electron bunches closer to the rf crest from the 5-th cell for a brisk acceleration.

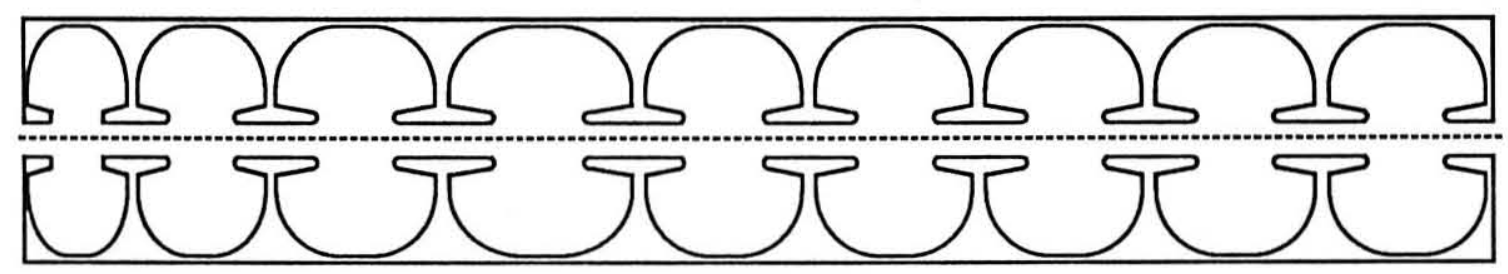

Figure 3. A schematic diagram of the L-band buncher. The lengths of the cells are: $7.5,9.8,11.7,13.5,11.7,11.7,11.7,11.7,11.7 \mathrm{~cm}$.

Solenoidal focusing is used from the gun to the end of the L-band buncher, and the quadrupole focusing thereafter. The beam energy at the end of the L-band buncher gives enough beam rigidity $(6 \mathrm{MeV})$ to traverse the long drift space for beam diagnostics and transition to quadrupole focusing.

Each linac tank is an L-band standing wave structure consisting of 27 side-coupledcavities. This configuration provides efficient acceleration with a high degree of mode stability for heavy beam loading. The strong inter-cell coupling assures that the phases and amplitude of the $\mathrm{rf}$ in each accelerating cell is identical with all the other ones in a given tank. Therefore, a sample of the rf field in one cell is representative of the whole accelerating tank. One coupling loops placed in each tank provides signals for precise feedback control and monitoring of each structure.

Particle simulation code PARMELA was used to study beam dynamics in the accelerator. The two low frequency bunchers are modelled as infinitely small accelerating gaps. The rf fields in the side-coupled cavities are calculated using fourteen Fourier-Bessel coefficients which were obtained from a SUPERFISH ${ }^{(9)}$ run. The same Fourier-Bessel coefficients with an appropriate scaling were used for calculating fields for cavities with slightly different 
dimensions as the L-band buncher cavities. Possible numerical errors were checked by simulating a simple laminar flow. From these test runs we found that numerical errors can cause emittance growth if the number of particles used in the simulation is too small or if the time step is too large.

Growths of the transverse and longitudinal beam emittances in the accelerator are calculated using PARMELA. They are shown in figure 4 and 5. Emittance growths were cause by (1) nonlinear space charge forces due to the spatial nonuniformity of the electron density, (2) longitudinal variations of the solenoidal focusing force during bunching, and (3) the timevarying radial $\mathrm{rf}$ fields in the accelerating structure. Small beam radius and gentle bunching are beneficial for low emittances. Calculated beam radii and the pulse duration are shown in figure 6 and 7.

We estimated the tolerance requirements for the gun parameters and the rf phases and the amplitudes by computing the sensitivities of beam energy and timing on these parameters. Several PARMELA runs with the identical initial electron distribution but different gun or rf parameters showed the sensitivity as summarized in Table VI. We note that the phase and the amplitude errors of the L-band buncher must be most tightly controlled because of their effect on the timing jitter.

Table VI. Sensitivity of the beam energy and the time-of-arrival on various errors

\begin{tabular}{lcrc}
\hline Error Source & Error Magnitude & $\mathrm{dE}(\mathrm{keV})$ & $\mathrm{dt}(\mathrm{ps})$ \\
\hline & $-15 \mathrm{psec}$ & 23 & -0.28 \\
Gun Timing Error & $1 \%$ & 41 & 0.39 \\
Gun Voltage Error & $-1 \circ$ & 41 & -0.20 \\
1st LFB Phase error & $-1 \circ$ & 34 & -0.15 \\
2nd LFB Phase error & $1 \%$ & 15 & -2.28 \\
L-Band buncher Amplitude Jitter & $1 \circ$ & -47 & -2.28 \\
L-Band buncher phase Jitter & $1 \%$ & 177 & -0.07 \\
Linac I Amplitude Jitter & $1 \circ$ & 19 & 0.00 \\
Linac I Phase Jitter & & & \\
\hline
\end{tabular}

\section{Summary}

The two design studies were performed independent of each other and were not optimized for the comparison purpose. However it is interesting to compare the parameters achieved and their potentials for future applications. The parameters of the rf gun and the IRFEL injector (column 2 of Table II) are compared in Table VII. 
Table VII. Comparison of the rf gun and the IRFEL injector

\begin{tabular}{lrr}
\hline Error Source & rf gun & IRFEL injector \\
\hline Energy $(\mathrm{MeV})$ & 5 & 6 \\
Charge/micropulse & 1 & 1 \\
Beam radius (mm rms) & 3.7 & 0.6 \\
Pulse length (mm rms) & 1.3 & 1.3 \\
Initial emittance $\left(\gamma \sigma_{\mathrm{X}} \sigma_{\mathrm{x}^{\prime}}\right.$ mm-mrad) & 0.56 & 2.5 \\
Exit emittance $\left(\gamma \sigma_{\mathrm{X}} \sigma_{\mathrm{x}^{\prime}} \mathrm{mm}-\mathrm{mrad}\right)$ & 13 & 6 \\
Longitudinal Emittance $\left(\sigma_{\mathrm{z}} \sigma_{\Delta \mathrm{E} / \mathrm{E}} \mu \mathrm{m}\right)$ & 30 & 40 \\
Time jitter $(\mathrm{psec})$ & 1 & 0.1 \\
\hline
\end{tabular}

The rf gun described in this report has parameters which appear to be not much better than those of the IRFEL gun. However, we believe that $r$ guns have a great potential of providing higher intensity brighter electron sources that the conventional injectors inherently can not achieve. The scaling laws for the rf gun suggest that smaller emittances may be achieved by reducing the beam size, pulse duration, and the bunch aspect ratio. This requires shorter laser pulses of higher intensity and external beam focusing. Reliability, stability, and the life time of the rf gun and the laser sistem must be improve to be used as a practical injector.

\section{References}

(1) "Conceptual Design of a Bright Electron Injector Based on a Laser-Driven Photocathode RF Electron Gun", S. Chattopadhyay, Y. J. Chen, D. Hopkins, K. J. Kim, A. Kung, R. Miller, A. Sessler, and T. Young, Proceedings of the 1988 Linear Accelerator Conference, Williamsburg, VA, October 2-7, 1988, page 325

(2) "Conceptual Design Report Combustion Dynamics Facility / LBL", LBL Report, PUB5250, February, 1990

(3) "Requirements and Accelerator Design of a Highly-Stable Infrared Free Electron Laser at LBL", K-J. Kim, M. Berz, S. Chattopadhyay, J. Edighoffer, R. Gough, C. Kim, A. Kung, M. Xie, and W. Stein, Proceedings of the European Particle Accelerator Conference, Nice, France, 12-16 June, 1990

(4) "Rf and Space-charge Induced Emittances in Laser-driven Rf Guns", K. J. Kim and Y. J. Chen, Proceedings of the 1988 Linear Accelerator Conference, Williamsburg, VA, October 2-7, 1988, page 322

(5) "Simulation of High-Brightness RF Photocathode Guns for LLNL-SLAC-LBL $1 \mathrm{GeV}$ Test Experiment", Y. J. Chen, LLNL pub. UCRL-99675 (1988)

(6) "Design of the Laser-Driven RF Electron Gun for the BNL Accelerator Test Facility", K. T. McDonald, IEEE Trans. on Electron Devices, (1988)

(7) "Timing Jitter Measurements at the SLC Electron Source", J.Sodja, M.J. Browne, and J. E. Clendenin, Proceedings of the 1989 IEEE particle Accelerator Conference, page 343

(8) E. A. Knapp, B. C. Knapp, and J. M. Potter, Rev. Sci. Instrum. Vol 39, 979 (1968)

(9) K. Halbach and R. F. Holsinger, Particle Accelerators, Vol 7, 213 (1976). 


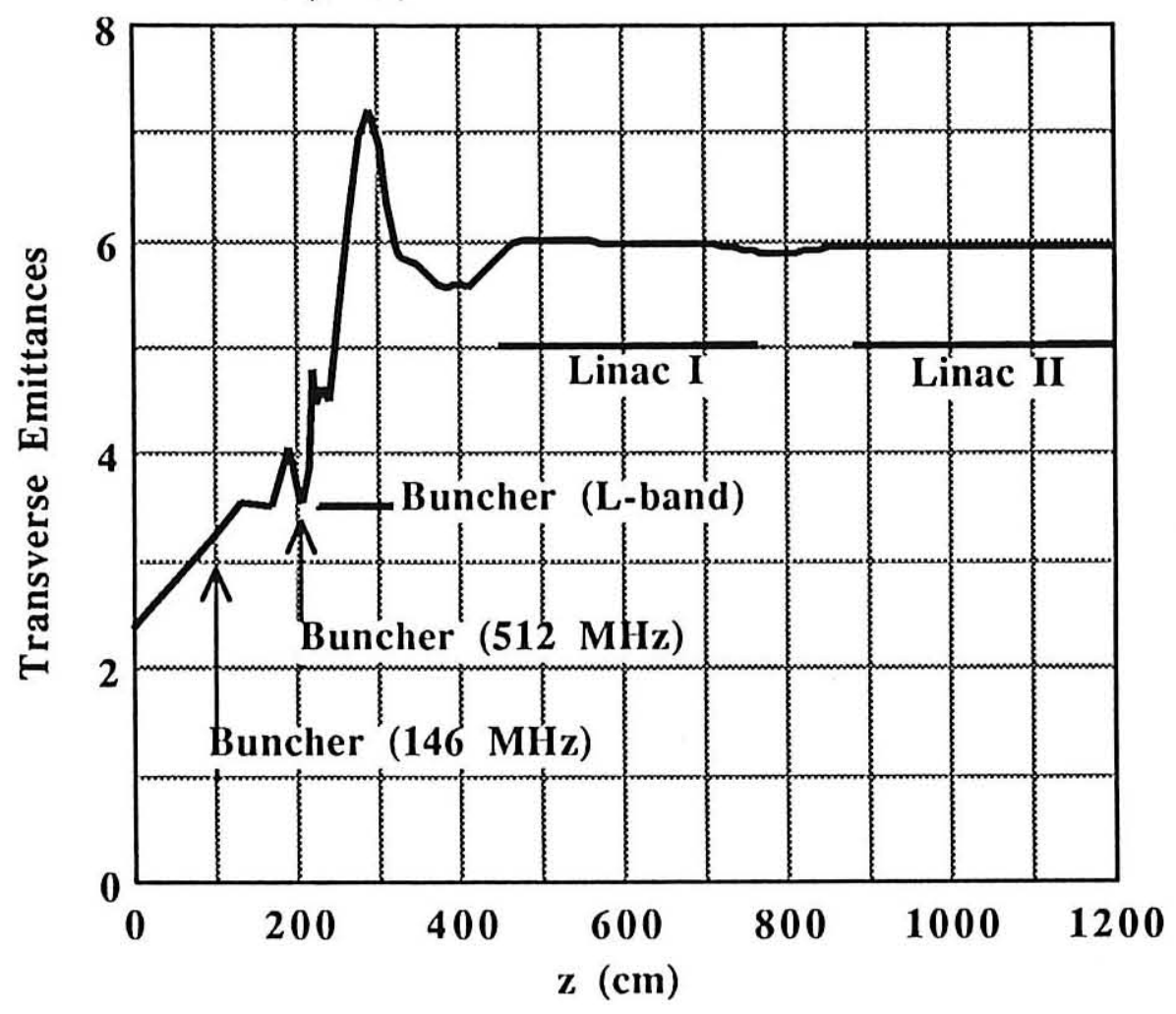

Figure 4. Transverse Emittance $\gamma \sigma_{\mathbf{x}} \sigma_{\mathbf{x}^{\prime}} \quad$ (mm-mrad)

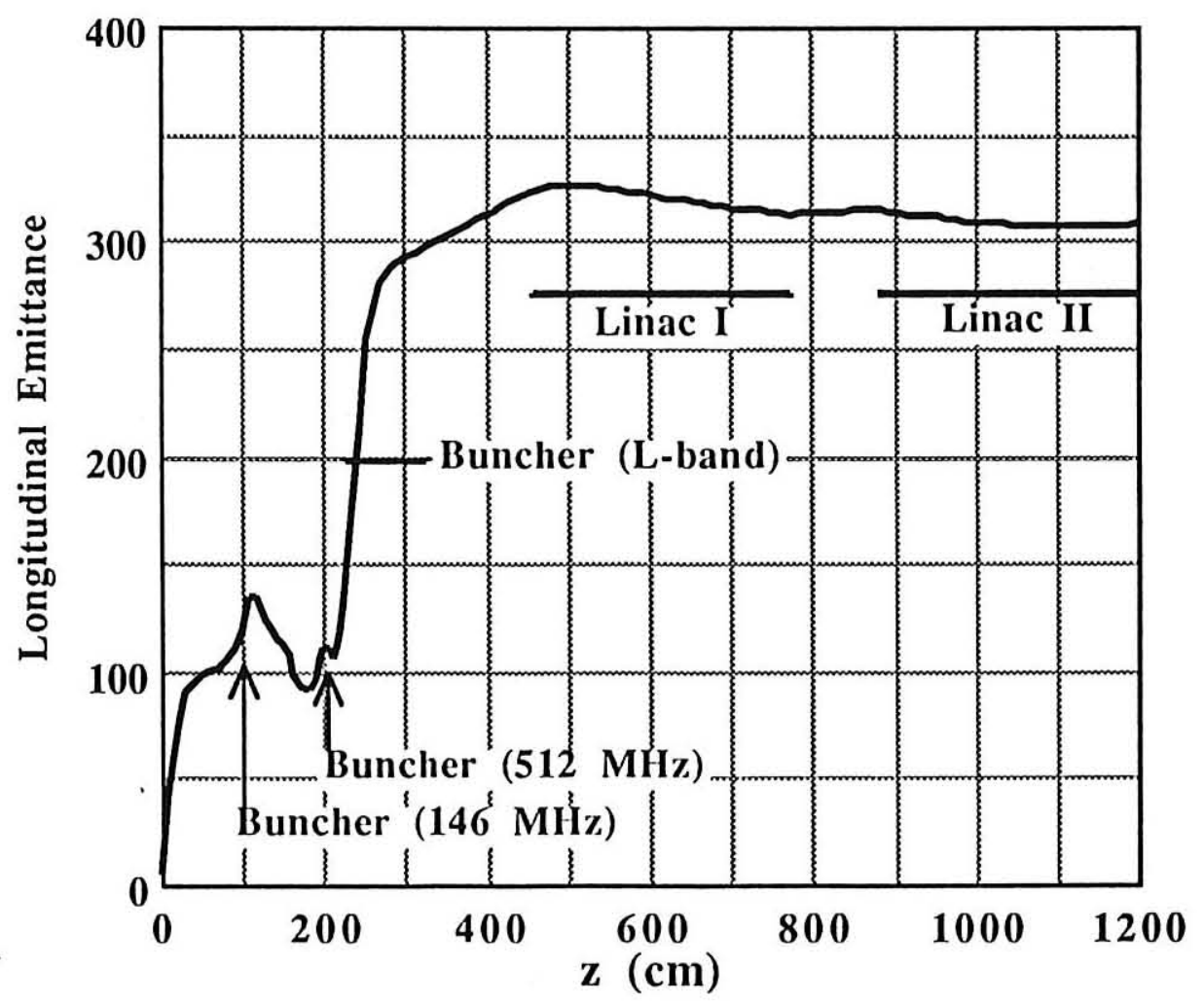

Figure 5. Longitudinal emittance $\sigma_{\delta \mathbb{E}} \sigma_{\phi} \quad$ (keV-deg) 


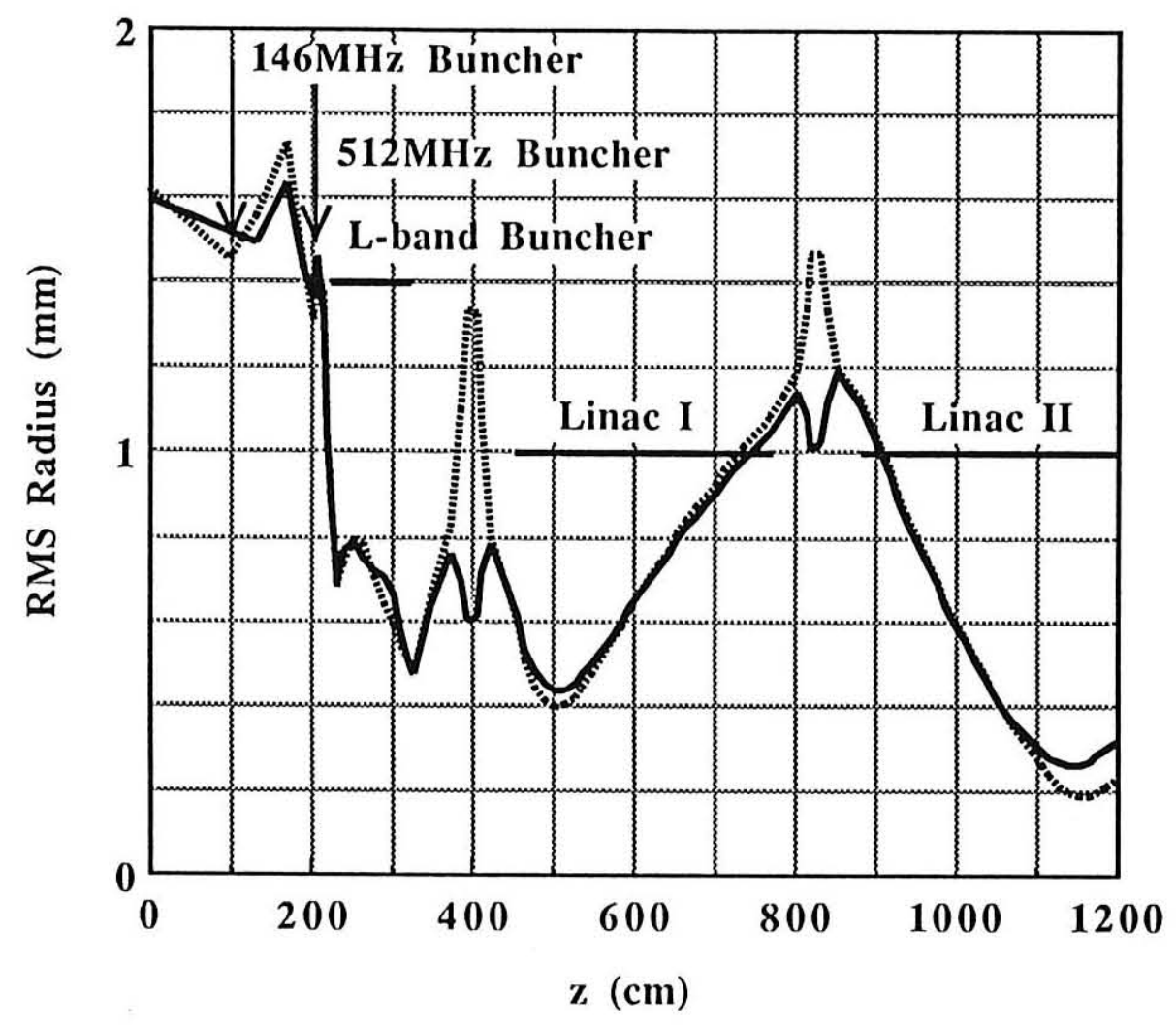

Figure 6 Beam radius (mm rms)

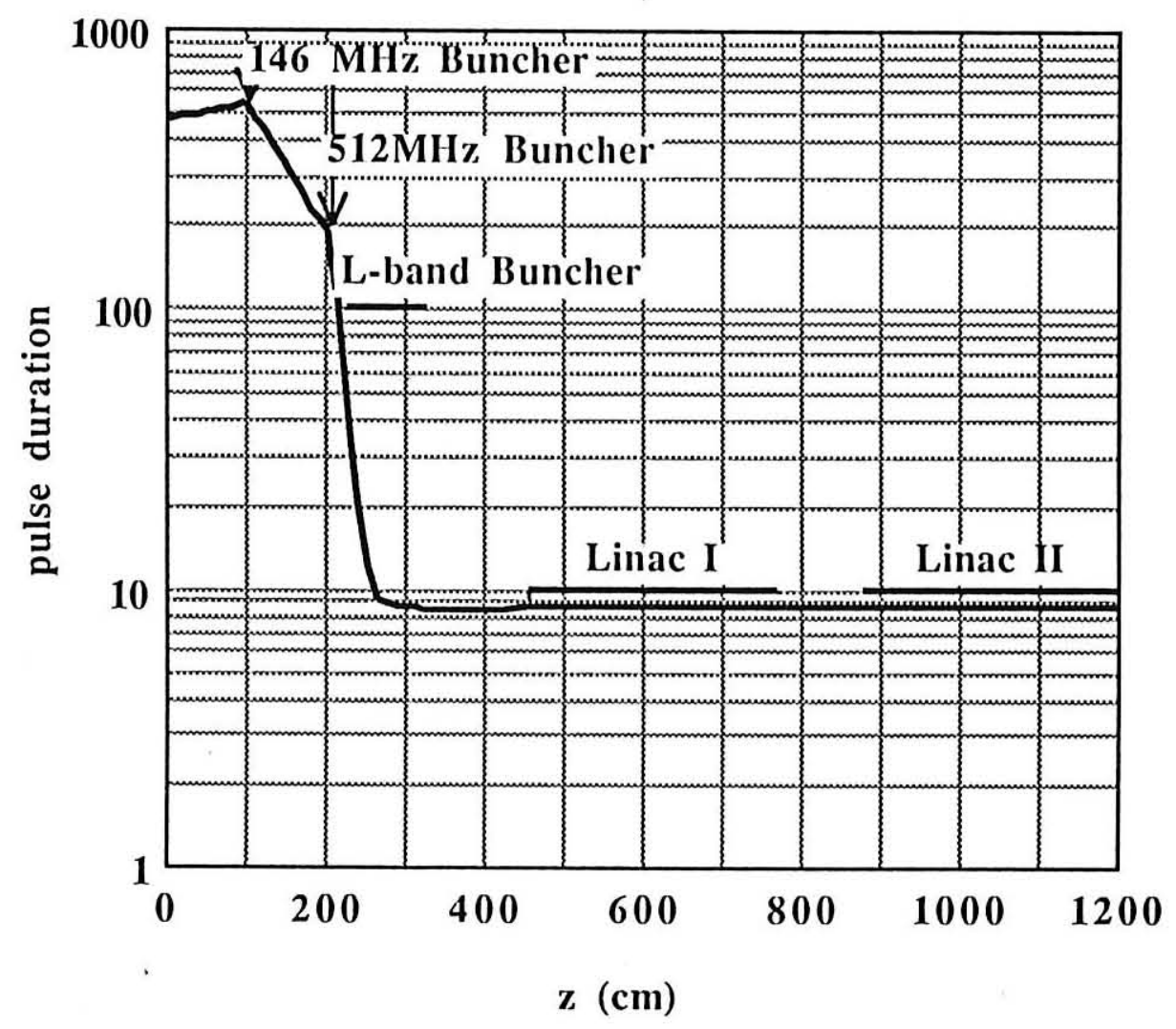

Figure 7. Pulse duration $2 \sigma_{\mathrm{t}}$ (psec) 